\title{
Resiliencia e Inteligencia Emocional: bosquejo de modelo integrador para el desarrollo del saber ser del estudiante universitario
}

\section{Anna Belykh}

\section{RESUMEN}

En este artículo analizamos dos constructos psicológicos de potencial utilidad para el desarrollo del saber ser, uno de los pilares de la educación para el siglo XXI formulados por la UNESCO. En la parte introductoria, resaltamos el carácter particular del saber existencial en este planteamiento educativo. Procedemos a bosquejar una propuesta para su desarrollo con base en los constructos de resiliencia e inteligencia emocional. Tras describir tres principales modelos de cada uno aplicables a educación superior, señalamos la complementariedad de dos de ellos para el fomento cognitivo del crecimiento personal del estudiante incidiendo en su formación integral.

Palabras clave: educación superior, resiliencia, inteligencia emocional, saber ser.

\section{Resiliencia e Inteligencia Emocional: bosquejo de modelo integrador para el desarrollo del saber ser del estudiante universitario}

\section{RESUMO}

En este artículo analizamos dos constructos psicológicos de potencial utilidad para el desarrollo del saber ser, uno de los pilares de la educación para el siglo XXI formulados por la UNESCO. En la parte introductoria, resaltamos el carácter particular del saber existencial en este planteamiento educativo. Procedemos a bosquejar una propuesta para su desarrollo con base en los constructos de resiliencia e inteligencia emocional. Tras describir tres principales modelos de cada uno aplicables a educación superior, señalamos la complementariedad de dos de ellos para el fomento cognitivo del crecimiento personal del estudiante incidiendo en su formación integral.

Palavras chave: educación superior, resiliencia, inteligencia emocional, saber ser.

\section{Resilience and Emotional Intelligence: outline of an integrated model for learning to be in} higher education

\begin{abstract}
In this article we analyze two psychological constructs of potential usefulness for the development of learning to be pillar of the UNESCO educational framework. In the introductory part, we highlight the particular character of existential knowledge in this educational approach. We proceed to outline a proposal for its development, based on the constructs of resilience and emotional intelligence. After describing three main models of each applicable to higher education, we point out the complementarity of two of them for the cognitive promotion of student's personal growth inthe face of their comprehensive training.
\end{abstract}

Key words: higher education, resiliency, emotional intelligence, learning to be.

Anna Belykh

Mexicana. Maestría en lingüística aplicada en la Universidad de las Américas Puebla. Estudiante de tiempo completo del doctorado en Ciencias de la Educación en la Universidad Autónoma de Tlaxcala (2016-2019), tesis en psicología educativa. Temas de investigación: resiliencia, inteligencia emocional, competencias para la vida, educación superior humanista/integral.

Recepción: 07/08/17. Aprobación: 08/10/18. 


\section{Introducción}

Desde el Informe Delors de la Comisión Internacional para la Educación del siglo XXI de la UNESCO (1996), se han establecido los saberes-base de la educación que queremos para las nuevas generaciones, $y$ éstos se manejan bajo el concepto de los pilares, que es muy popular hoy en una sociedad que se construye y se reconstruye ante nuevos contextos y retos de diversas índoles. Así, estaríamos frente a "una utopía necesaria", un proyecto de construcción educativa cuyo resultado es la formación académica que queremos y necesitamos para el siglo XXI (Delors et al., 1996). Sabemos que los primeros tres pilares son aprender a conocer, a hacer y a convivir de los cuales se desprenden las competencias sapienciales, procedimentales y actitudinales. El cuarto pilar - aprender a ser - se refiere al proceso fundamental que recoge los tres pilares anteriores e implica desarrollar la propia personalidad, autonomía de juicio y responsabilidad personal (Delors et al., 1996: 91).

Este planteamiento indica cuatro grandes vertientes de la educación sin especificar secuencias o prioridades, y su representación gráfica tradicional es la de la entrada a un templo antiguo, como el Templo de Apolo en Delfos cuya entrada perpetra el imperativo de conocerse a uno mismo (Negrete, 2013). La estructura romana brinda una representación algo confusa donde los pilares se apoyan en los procesos de aprendizaje (los cimientos) para lograr una educación (el techo), y resulta debatible que la educación sea la meta en sí y el aprendizaje cese una vez que se logren los objetivos educativos oficiales.

De igual manera, es de destacarse que esta representación deja desatendido el carácter particular del cuarto elemento relacionado con la personalidad de los actores educativos. Es decir, la descripción del último pilar como aquel que se apoya en los tres anteriores para su formación hace pensar en una estructura tipo Stonehenge antes que en un pórtico con columnas romanas cuya imagen inspirada en el logotipo de la UNESCO se suele utilizar. Diríamos que un Stonehenge plasmaría mejor la idea que la meta de una educación formal es un aprendizaje continuo autorregulado a lo largo de toda la vida para un desarrollo del ser que trascienda el ámbito educativo, y no esté "techado" por el mismo (véase figura 1).

\section{Figura 1. Construcción romana versus estructura tipo Stonehenge para representar los saberes del Informe Delors}

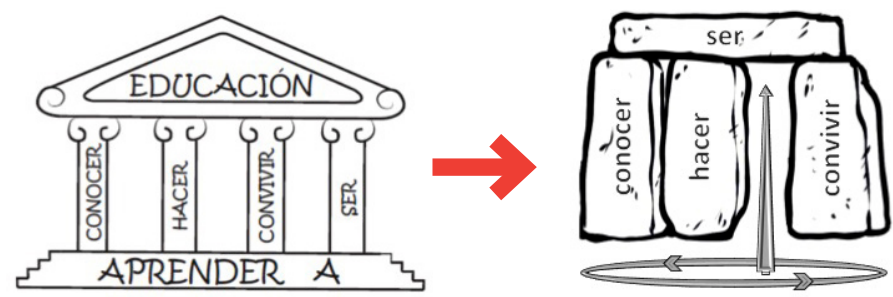

Fuente: elaboración propia con datos de la Delors et al, 1996.

Stonehenge es una estructura inglesa milenaria circular, construida - al igual que varias otras en el mundo entero que se le asemejan en forma y propósito - para fomentar la unión social y llevar a la sanación individual a los partícipes de los rituales que se desenvolvían a su alrededor (Romero, 2016). Por ello, esta nueva representación de las competencias para la vida en el siglo XXI resulta más que apropiada en una sociedad donde, a pesar de que se han vencido muchas barreras que solían separarla 
- sobre todo físicas-, aún se necesita vencer algunas barreras mentales para la unión global y sanar secuelas de crisis e inequidad que se han vivido. Sin duda alguna, la educación tiene mucho que ver en esta labor. Otra visualización posible para los saberes educativos del Informe Delors es la de un Guidestone que es una estructura que contiene indicaciones para turistas en distintos idiomas y cuyo propósito principal es ayudarles a definir su camino (véase figura 2).

\section{Figura 2. Marco educativo Delors como Guidestone}
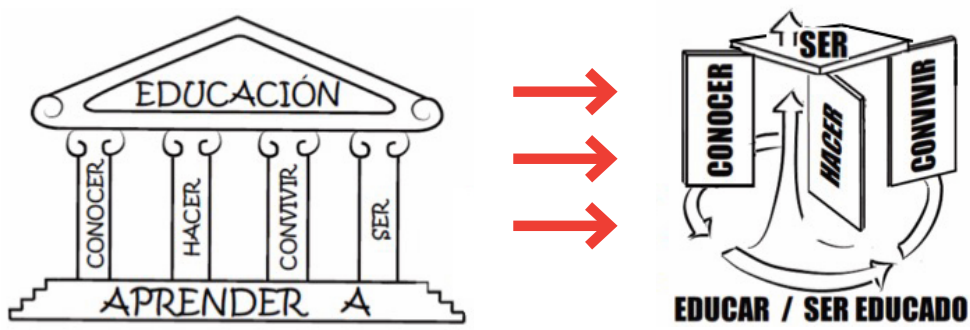

Fuente: elaboración propia con datos de la Delors et al., 1996.

Esta función de comunicación diversificada es muy apropiada para el ámbito educativo, no sólo para referirse a la educación bilingüe o políglota tan necesaria en este mundo globalizado, sino para representar la naturaleza multifacética de los procesos de aprendizaje que se activan de manera simultánea frente a los contenidos educativos. Entre esas facetas se pueden mencionar las siguientes: 1) canales de aprendizaje (auditivo, kinestésico y visual, O’Brien, 1990); 2) estilos de aprendizaje (activo, reflexivo, teórico y pragmático, Alonso y Gallego, 2008), y 3) inteligencias múltiples (intra e interpersonal, musical, lógico-espacial, lingüística, visual-espacial, manual-kinestésica, naturalista e incluso existencial y pedagógica — estas últimas dos se encuentran en periodo de sustentación científica para poder ser incluidas en el rango de las inteligencias múltiples (Gardner, 1983).

Una mediación del aprendizaje basada en la implicación de la mayor cantidad posible de estas facetas que conlleve el uso de diversos lenguajes y la presentación de la información en distintas modalidades brindaría oportunidades más equitativas de aprendizaje a todos los estudiantes, al no estar orientada mayormente a un perfil definido de estudiante - auditivo, teórico-reflexivo y lingüísticamente inteligente-, en detrimento de otros estilos, canales de aprendizaje e inteligencias. Así, toda vez que la aplicación de este entendimiento del carácter complejo del aprendizaje vaya más allá de etiquetar a los aprendientes, que no los deje a solas con la responsabilidad de descubrir y poner en práctica la utilidad de dichas etiquetas, que genere más bien conciencia de diversidad sensorial y cognitiva en el aula y abone a planeaciones didácticas diversificadas, estaremos más cerca de aprovechar todos los recursos que poseemos sin importar ligeras tendencias o preferencias individuales, y se habrá progresado hacía una formación más integral e inclusiva.

Todos estos planteamientos expresan la necesidad de una educación para la vida conectada con el contexto y con las características del estudiante, de una educación social y emocional; sin embargo, por lo general, desde los documentos de los organismos internacionales que promueven su integración en la educación formal, no se hace referencia a un marco de acción único y bien estipulado para poder hacerla 
realidad. Sigue siendo un tema relativamente nuevo que en México se ha abordado recientemente desde las competencias socioemocionales en educación básica y secundaria, y en educación superior se ha ido incorporando desde algunos modelos humanistas locales, sin un marco de referencia común a nivel nacional y sin propuestas de su evaluación objetivada.

Parte de la dificultad de regularizar su implementación en las universidades reside en la tendencia general a la disminución de materias del ámbito de humanidades y cada vez mayor enfoque en el saber hacer (Pleshakova, 2009, entre otros). Más allá de la discusión sobre las carreras en humanidades (que se da en el foro del Arts and Humanities in Higher Education fournal, por ejemplo), aquí reivindicamos la relevancia de materias de artes y humanidades en el tronco común para los estudiantes de cualquier carrera, las cuales a su vez deberían ir más allá del conocimiento enciclopédico y reorientarse hacia las competencias para la vida. El contenido de las materias como literatura, filosofia, arte e idiomas tiene un gran potencial para entretejer sus contenidos con el desarrollo personal enfocado desde un saber ser. Sería una especie de regreso al concepto de educación integral en la época de Renacimiento, cuando los humanistas recibían una instrucción tanto moral y lingüística como científica y artística, sin que ésta se limitase a las clases privilegiadas.

Para encontrar las maneras de incorporar el saber ser en las materias actuales de tronco común - sustentando ese elemento humanista que figura en varios programas universitarias mexicanos - es indispensable un acercamiento interdisciplinar entre la educación y la psicología, dando como área de investigación la psicología educativa (o la educación psicológica: término poco utilizado, pero que consideramos igualmente válido y quizá más exacto en nuestro planteamiento, ya que va dirigido a actores educativos que buscan caminos para el desarrollo del ser en su práctica diaria antes que a los psicólogos que acompañan los procesos educativos auxiliando en caso de crisis).

En este acercamiento entre la educación y la psicología, dirigimos nuestra mirada a dos constructos psicológicos relacionados con la potenciación de la personalidad exitosa: la resiliencia y la inteligencia emocional. Esto para alcanzar el objetivo de la presente revisión teórica que consiste en fundamentar la vinculación entre los dos constructos con el propósito de generar una propuesta de modelo integrador para el desarrollo del saber ser en el ámbito de educación superior.

El método que sustenta esta revisión consiste en lectura crítica y análisis teórico-epistemológico de los principales modelos de resiliencia e inteligencia emocional que fueron mencionados en los artículos revisados en el marco del estado del arte ${ }^{1}$ del proyecto doctoral en curso cuyo marco teórico aquí se resume. Los criterios de inclusión fueron, además de su reiterada presencia en los estudios actuales de investigación educativa, su aplicabilidad a adultos desde el planteamiento original de sus autores. El análisis se basó en las publicaciones originales de los autores de dichos modelos, así como las críticas principales hacia las mismas, y sus resultados se exponen desde una postura crítica propia bajo el enfoque del objetivo de la presente revisión.

\section{Resiliencia}

En este apartado presentamos tres modelos de la resiliencia, cada uno formulado desde una perspectiva distinta, pero todos convergiendo en la búsqueda de contenidos temáticos, perfiles docentes prolíficos o valores y fortalezas individuales de los actores educativos necesarios para la construcción de una personalidad que sea capaz de enfrentarse a las dificultades con buena actitud y sin bajar su rendimiento, una

\footnotetext{
${ }^{1}$ Este apartado de la tesis (sin publicar) abarcó la temporalidad de 20 años (1997-2017) sin restricciones geográficas, con palabras clave de resiliencia, inteligencia emocional y educación superior/estudiantes en distintas combinaciones (resiliency/resilience, emotional intelligence, higher education/college students en inglés) y se basó en los repositorios Dialnet, Scielo, TDR, TESIUNAM, EBSCO, PsychInfo y Web of Science.
} 
personalidad resiliente. Destacamos que aquí la resiliencia se retoma en su concepto no clínico, fuera de contextos traumatizantes o vivencias dolorosas. Los modelos abordados tienen como común denominador la búsqueda de éxito del individuo en el ámbito académico y más allá. Cada uno tiene algo que ver con el buen manejo de las emociones como parte del contexto o de los procesos relacionados con la construcción de la resiliencia. Este hecho nos permite relacionar posteriormente esta línea de investigación con la inteligencia emocional.

El primer modelo de la resiliencia que abordaremos es de autoría de Vanistendael y Lecomte (2002) quienes plantean que la resiliencia se asemeja a una casa (incluso la llaman "casita de la resiliencia"). Este modelo apunta a la naturaleza cercana y de continuo mantenimiento del constructo: "La casita es símbolo del hogar - donde hay vida - y no tiene una estructura rígida: ha sido construida, tiene su historia, necesita recibir cuidados y hacer reparaciones y mejoras, las distintas habitaciones se comunican mediante escaleras y puertas (al igual que los diferentes elementos que promueven la resiliencia)" (Orteu, 2012: 19).

Las distintas actividades o programas de intervención son por tanto consideradas "reparaciones", "muebles", "decoraciones", sugiriendo que es mejor intervenir en varias "habitaciones" a la vez, siempre tomando en cuenta los materiales con los que está construida una casita (construcción sociocultural del individuo, véase figura 3).

\section{Figura 3. La casita de la resiliencia de Vanistendael y Lecomte}

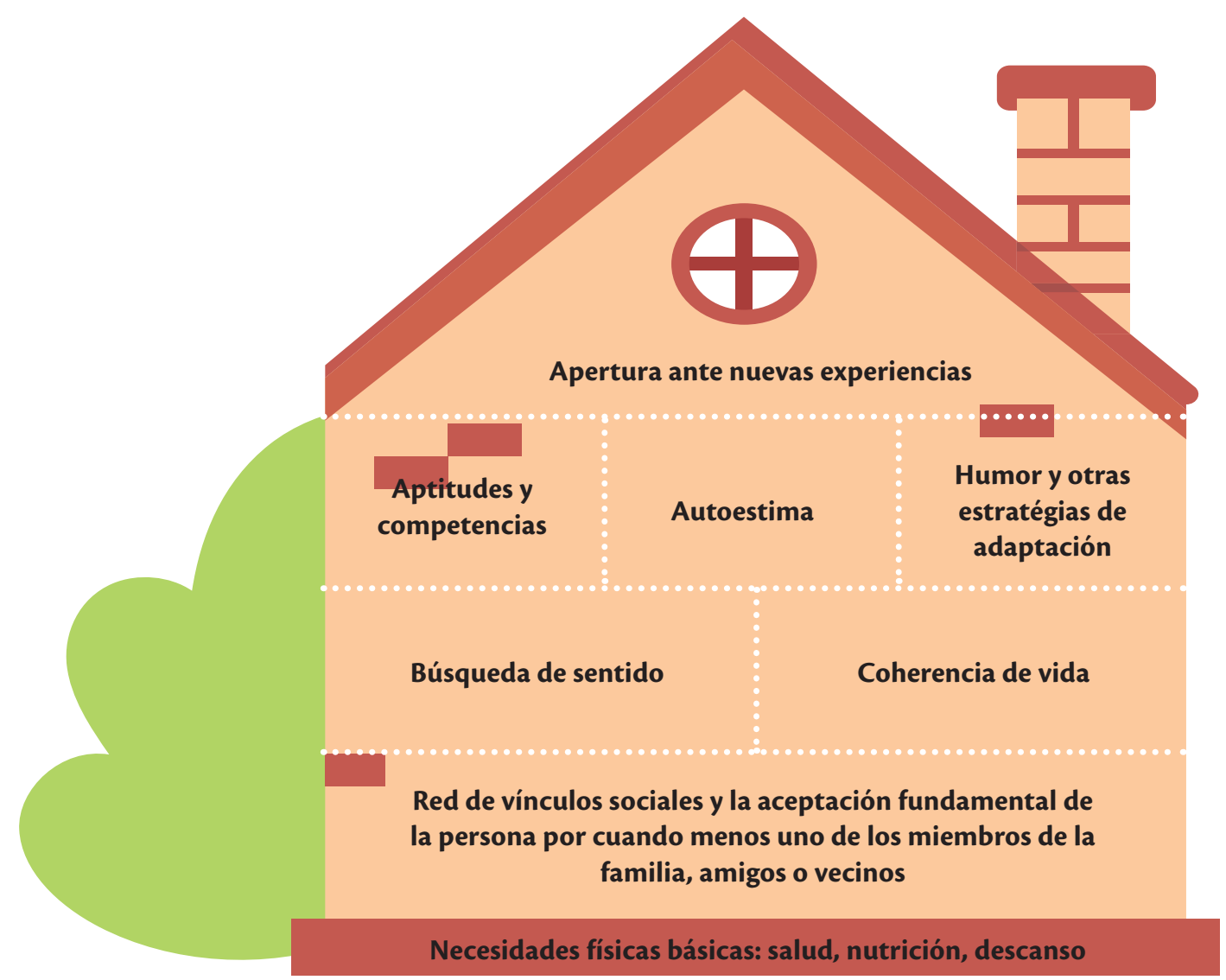


Resulta valioso el hecho de que este modelo abarca algunos aspectos generalmente se dan por sentados, yendo desde lo básico como el cuidado personal, que es indispensable atender antes de pensar en estudiar cualquier fenómeno sociológico positivo, procede a lo desarrollado desde las teorías del apego, para finalmente escalar a los factores de protección en forma de redes relacionales. El siguiente nivel consecutivo es el de espiritualidad y pensamiento crítico, y el último es el que correspondería a los aprendizajes escolares y de superación personal wcoronados con una disposición general de apertura a todo tipo de nuevos acontecimientos como resultado. Otro aspecto importante es hacer notar que, por lo general, en la escuela nos concentramos en el cuarto central de la planta alta de "la casita" mientras que sería importante armonizar la "decoración" de todo del hogar de la resiliencia.
A pesar de señalar valiosos insights resultantes de esta investigación, la ordenación de los elementos como sentido y coherencia de vida, siendo niveles inferiores al de aptitudes o humor, es debatible; por ello, sin descartar estos elementos de alta pertinencia en el contexto europeo, el modelo no se retomó como base. Es curioso notar que si dejamos de lado la estructura de la casita que viene a la mente por asociación con el término de la construcción - muy utilizado al adoptar la perspectiva constructivista en ciencias sociales - y si excluimos las etapas de "suelo" y "sótano" como pertenecientes a la vida social no educativa de la persona, quedan seis apartados para el desarrollo de la resiliencia en la escuela. Estos seis espacios resultantes podrían ser plasmados en forma de diagrama propio de representaciones tanto matemáticas como espirituales y filosóficas (véase figura 4).

Figura 4. Niveles de la "casita de la resiliencia" aplicables al ámbito educativo

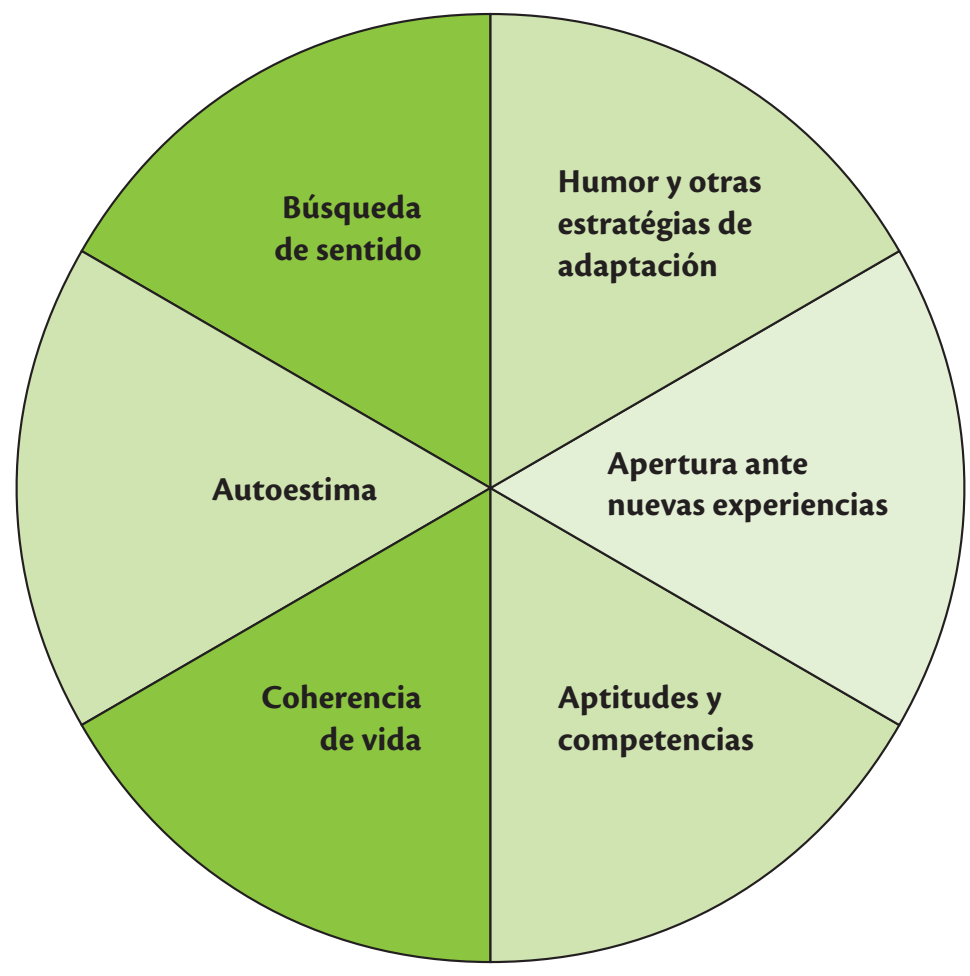

Fuente: elaboración propia con datos de Vanistendael y Lecomte, 2002. 
Además de conectar el modelo de la casita con el Stonehenge y el círculo de la vida, esta representación es uniforme con el siguiente modelo, el de la rueda de la resiliencia de Henderson y Milstein (2005). Estos autores formulan la rueda de la resiliencia: un esquema de seis pasos que contribuye a la construcción de la resiliencia en la escuela. Este esquema está relacionado con un perfil docente que reúne actitudes, creencias, valores y emociones propias de un docente resiliente (véase figura 5).

Figura 5. Perfil docente basado en la rueda de la resiliencia

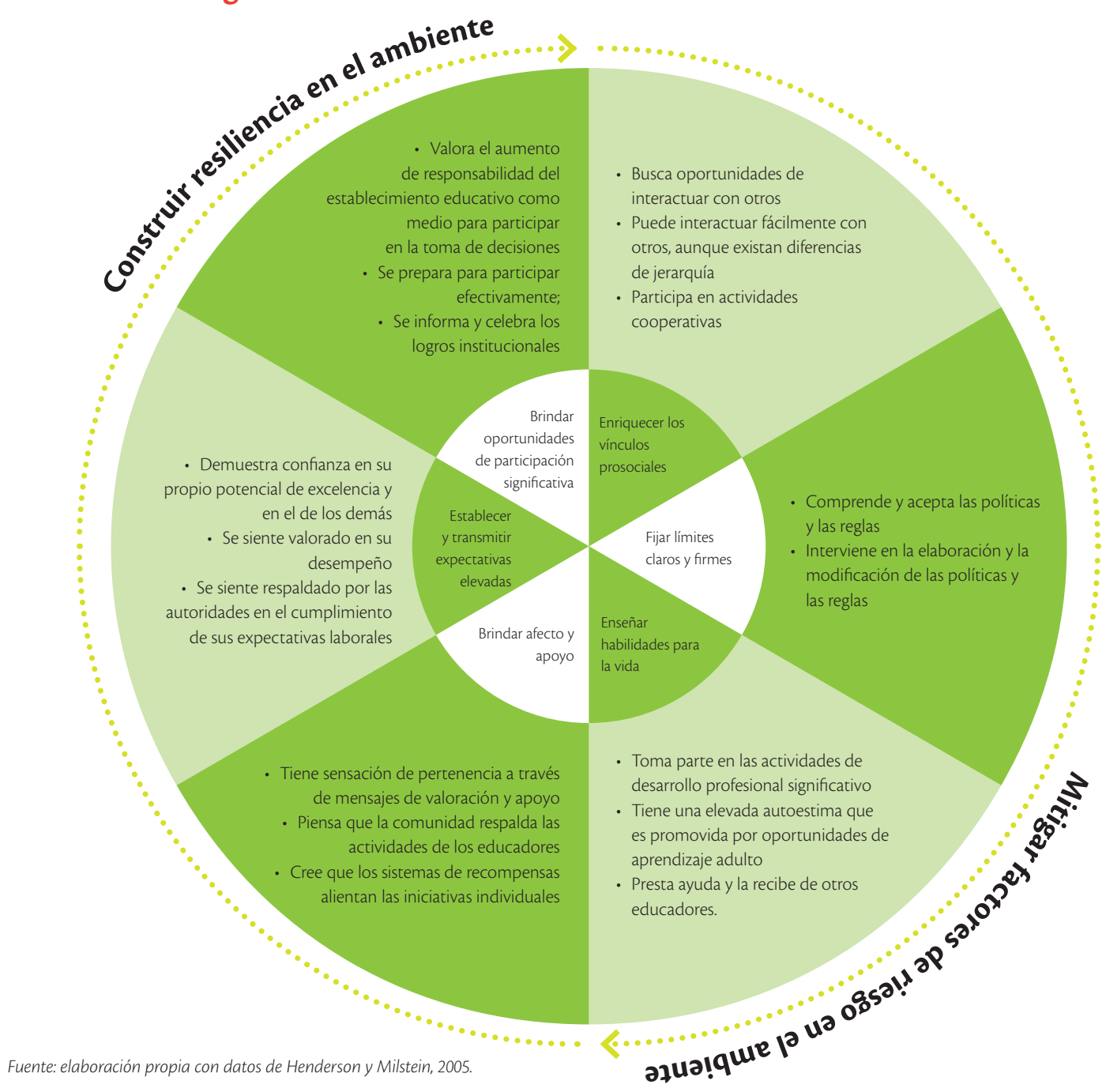

Este es un modelo para la construcción de una personalidad docente resiliente, resultado de un esfuerzo investigador enfocado en formulación de una base para la capacitación docente con el fin de instruirnos como tutores de resiliencia. Para ello se estudiaron los profesores más positivos y productivos en varias escuelas argentinas y se elaboró un perfil a partir de sus actitudes y comportamientos. Al basarse en buenas prácticas locales, este modelo no está exento de limitaciones, puesto que es notable que éste en parte depende del contexto institucional, y que por más resiliente que se pueda ser, uno no puede negar algunas realidades. Por ejemplo, la creencia de que la comunidad respalda las acciones de los 
educadores sería difícil de mantener si el contexto inmediato permitiera cuestionamientos infundados de padres de familia, como suele suceder en las instituciones educativas contemporáneas. Se volvería casi imposible seguir creyendo en la existencia de tal respaldo si la institución educativa viera al padre de familia como al cliente que siempre tiene razón.

A su vez, los mensajes de valoración y apoyo también dependen del entorno: este rubro parece más bien un mensaje indirecto a la administración para que preste atención a estos detalles. Lo mismo se puede decir de sentirse respaldado por las autoridades en el desarrollo de su carrera: lamentablemente no siempre es el caso, y la postura de Cándido de Voltaire no es ni debería ser parte de las competencias docentes. Valorar el aumento de responsabilidad también es un descriptor ambiguo: algunas responsabilidades no implican participación en la toma de decisiones (grupos numerosos, mayor cantidad de exámenes y tareas por revisar o más horas de asesoría o frente al grupo, por ejemplo), y sin el debido aumento de sueldo o descarga académica pueden ser difíciles de apreciar. En este sentido, quizá sería más atinado destacar una actitud proactiva del docente resiliente ante las condiciones en las que se encuentra, creación de sus propias condiciones favorables, y no una visión favorable de las mismas sea cual sea la realidad.

En resumen, el modelo de Henderson y Milstein es un modelo de construcción de la resiliencia con recursos propios (creencias, actitudes y acciones del docente) y los recursos del contexto (políticas institucionales y ambiente laboral). Esta integración podría ser contraproducente para evaluar la resiliencia ya que afectaría los resultados al no estar dados los recursos del contexto. Con esto en mente, consideramos muy valioso su planteamiento estructural y lo retomaremos para el análisis del tercer modelo de resiliencia. Éste nace en el ámbito de la psicología positiva. En un estudio de textos religiosos y filosóficos de muchas partes del mundo, Peterson y Seligman
(2004) analizaron y clasificaron virtudes y fortalezas que se les atribuyen a personas plenas de manera transversal en las principales corrientes filosóficas y teológicas.

En los resultados de esta investigación que duró cinco años los autores logran acotar seis virtudes y 24 fortalezas, mismas que tienen gran afinidad con las teorías de resiliencia cuando se entienden como rasgos de personalidad. Las fortalezas son medibles y adquiribles, lo cual hace que el modelo sea apropiado para el ámbito educativo, el cual trabaja a partir de este supuesto. Con base en el test desarrollado por los autores para medir estas fortalezas, se concluye que en promedio todos tenemos al menos cinco fortalezas desarrolladas que favorecen nuestra resiliencia, y podemos desarrollar las demás para potenciarla.

En la figura 6 se aprecia esta clasificación de virtudes y fortalezas organizadas según la virtud que ayudan a alcanzar y graficados a manera de la rueda de la resiliencia de Henderson y Milstein (2005). La diferencia con este último modelo es que la parte central está subdividida en dos círculos centrales para una presentación detallada de los elementos resilientes de la persona, la cual resulta adecuada en la búsqueda de modelos para un desarrollo integral del educando que ofrezca amplios marcos de referencia y ámbitos de acción variados.

El círculo externo se podrá llenar con acciones o rasgos de personalidad propias de un sujeto resiliente, pero la construcción de un perfil no es el propósito en este documento. En un futuro ese espacio permitiría desglosar cada una de las fortalezas en comportamientos esperados en individuos resilientes (fuertes o fortalecidos), así como definir de una manera mucho más específica el estado de la resiliencia del actor educativo y enfocar la acción educativa con mucha mayor precisión.

$\mathrm{Al}$ ser un modelo de amplio alcance, incluye algunos elementos que se pueden desarrollar cognitivamente en la escuela, y otros a cuyo desarrollo 
podemos contribuir sólo indirectamente al predicar con el ejemplo o alentar al estudiante (en la función de tutor de resiliencia). Con esto último nos referimos a la apertura, curiosidad, creatividad, amabilidad, optimismo, sentido del humor y persistencia que facilitan la permanencia y mantienen el interés y buen ambiente en cualquier salón de clase, aunque no se enseñan directamente en un aula universitaria.
Consideramos pertinente resaltar que, aun eliminando este último tipo de fortalezas, la clasificación de Peterson y Seligman (2004) sigue siendo más amplia que la de otros modelos del constructo, y su fundamentación en un estudio filosófico y teológico exhaustivo le brinda solidez, por esas razones lo preferimos ante los otros dos modelos anteriormente analizados.

Figura 6. Base de la resiliencia de Seligman

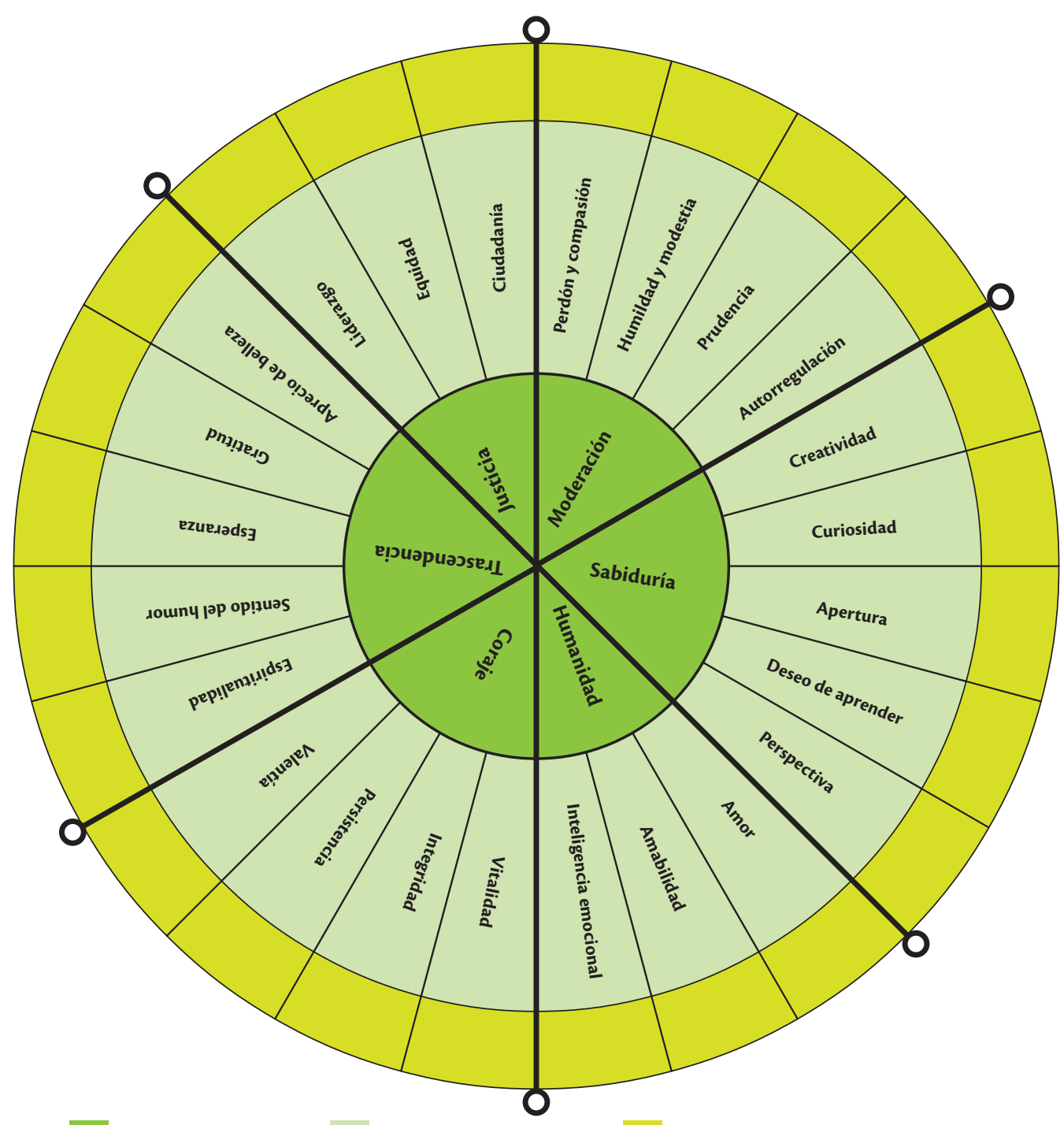

Valores

Fortalezas

Rasgos y/o comportamientos 
A pesar de no ser exento de algunas críticas (Gancedo, 2007), en su totalidad este tercer modelo tiene mucho potencial para contribuir a la formación de un buen ciudadano, justo, agradecido, constructivo, proactivo y con una visión del mundo optimista y esperanzada: el gran ideal detrás de la actividad educativa que se piense humanista, integral y empoderadora. No obstante, cuando lo que se busca es instrumentar una intervención educativa centrada en el estudiante, el modelo puede necesitar ciertas adaptaciones. Nos referimos justamente a enfocarse en el desarrollo cognitivo de éstas en el marco de la educación formal. Para ello, nos remitiremos al concepto de la inteligencia emocional - por la íntima relación entre los objetos de estudio de las dos líneas de investigación - en búsqueda de un acercamiento que permita ir más allá de una presencia benevolente en la vida del educando y posibilite una acción educativa estructurada.

\section{Inteligencia Emocional}

En este apartado abordamos brevemente la aparición del concepto de la inteligencia emocional, que parece combinar lo incompatible. Habiendo explicado cómo los investigadores han llegado a conciliar la razón y la emoción en un solo constructo, mencionaremos tres modelos de la inteligencia emocional seleccionados analizando su complementariedad con la clasificación de fortalezas, o rasgos resilientes, de autoría de Peterson y Seligman (2004).

La línea de investigación sobre la inteligencia emocional se desprende de una perspectiva planteada en la obra de Gardner (1983) sobre múltiples inteligencias personales, la cual tendió puentes entre el concepto de la inteligencia meramente cognitiva, heredada y estática a lo largo de la vida humana, y una tradición de investigación sobre las competencias sociales iniciada por Dewey a inicios del siglo XX, un concepto adaptable y desarrollable por definición.

La capacidad de razonar, el saber desenvolverse socialmente así como entender y apreciar la vida, el arte, el movimiento y la naturaleza, encontraron cabida en el nuevo concepto de la inteligencia que empezó a entenderse no sólo como una capacidad para resolver problemas lógico-matemáticos, sino como la capacidad de ser exitoso y vivir una vida plena en armonía consigo mismo y con su entorno natural y social (de donde viene la ampliación de las metas educativas Delors hacia el saber ser y el saber convivir, o bienvivir). Todo ello implica un balance emocional en los ámbitos personal e interpersonal; por tanto, el manejo de las emociones se vuelve parte del concepto de la inteligencia y del perfil de un sujeto inteligente.

El concepto de la inteligencia emocional emerge del análisis de dos de las inteligencias personales de Gardner (1983): la intrapersonal y la interpersonal. A nivel conceptual, el tema fue trabajado por una docena de equipos de investigadores alrededor del mundo, de los cuales los más reconocidos en el ámbito son John Mayer y Peter Salovey (Salovey y Mayer, 1990; Mayer y Salovey, 1997, 2007), Daniel Goleman (1995, 2001) y Reuven Bar-On (1997, 2000). Los esquemas de conceptualización se pueden clasificar en dos grandes categorías: inteligencia emocional como capacidad cognitiva e inteligencia emocional como rasgo de personalidad (Bisquerra, Pérez y García, 2015), aunque el modelo de Bar-On ha sido erróneamente traducido al español como habilidad (del inglés ability), resultando en que algunos autores distingan tres distintos acercamientos al estudio de la inteligencia emocional (por ejemplo, en Carrido y Talavera, 2008).

A continuación, detallaremos estos tres modelos: el modelo de Mayer y Salovey (1997) por ser el único en cumplir con el criterio cognitivo, y los modelos de Bar-On y de Goleman por estar basados en rasgos de personalidad más divulgados e investigados hoy en día. Tendremos en mente la búsqueda de elementos estructurantes para la articulación del marco teórico-práctico para el estudio de saber ser desde la construcción de la resiliencia para su análisis. 
En cuanto a la línea de investigación de Salovey y Mayer, es interesante remarcar que el primer planteamiento de los fundadores de la línea de investigación sobre la inteligencia emocional fue uno basado en rasgos de personalidad. Ese modelo de Salovey y Mayer (1990) se llama PEUR (percepción, expresión, uso y regulación). Las siglas del modelo corresponden a la palabra peur en francés, la cual significa "miedo", por lo que el cambio del nombre del modelo a PEFUR en su edición de 1997 resulta apropiado. Además del nombre, ese nuevo modelo revisa y fundamenta el planteamiento de la inteligencia emocional como capacidad cognitiva (ability model) y reestructura sus categorías quedando las cuatro de la siguiente manera: percepción y expresión, ${ }^{2}$ facilitación, uso, ${ }^{3}$ regulación (véase la figura 7).

\section{Figura 7. Modelo de inteligencia emocional como capacidad cognitiva}

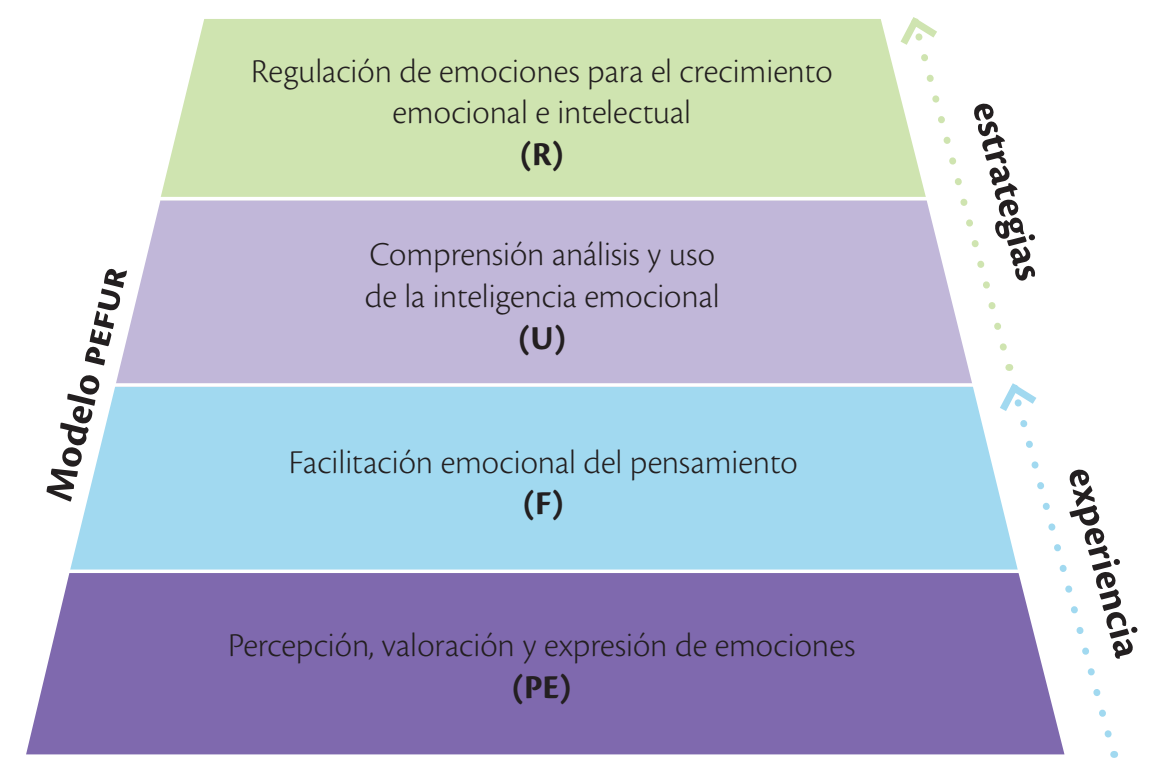

Fuente: elaboración propia con datos de Mayer y Salovey, 1997.

Este modelo divide el potencial cognitivo en cuatro áreas, las cuales se reagrupan en dos grandes ámbitos: experiencial y estratégico, y se subdividen en cuatro capacidades cada una. Las 16 capacidades se compaginan con las inteligencias inter e intrapersonal de Gardner, aunque no de manera explícita. El modelo ha recibido mucha atención por parte de los investigadores en inteligencia emocional y, con base en críticas y contribuciones de los colegas, Mayer, Caruso y Salovey (2016) recientemente afinaron esta clasificación con el fin de ofrecer una base más detallada y reflexionada para el acercamiento cognitivo al desarrollo de la inteligencia emocional; algunas capacidades se desglosaron en varias, otras se desdoblaron en los planos intra e interpersonal, dando como resultado 26 capacidades en vez de 16 (véase tabla 1).

\footnotetext{
${ }^{2}$ La versión castellana de Bisquerra et al., 2015, explicita dos tipos de capacidad presentes en esta categoría llamada en inglés sólo como perceiving emotion.

${ }^{3}$ La versión castellana por Bisquerra et al., 2015, de la categoría original en inglés understanding.
} 
Tabla 1. Modelo PEFUR 2016

\begin{tabular}{|c|c|c|}
\hline & Capacidades de inteligencia intrapersonal & Capacidades de inteligencia interpersonal \\
\hline $\begin{array}{l}\text { Percepción y } \\
\text { Expresión }\end{array}$ & $\begin{array}{l}\text { 1. Reconocer sus emociones debidas al estado físico, sentimientos y } \\
\text { pensamientos } \\
\text { 3. Percibir contenido emocional en el entorno, artes visuales y música' } \\
\text { 5. Entender manifestaciones emocionales según su contexto y cultura' }\end{array}$ & $\begin{array}{l}\text { 2. Percibir emociones de otros por tono de voz, expresión facial, lenguaje y } \\
\text { comportamiento' } \\
\text { 4. Expresar sus emociones con exactitud cuándo se desea } \\
\text { 6. Distinguir expresiones emocionales exactas de inexactas' } \\
\text { 7. Reconocer sinceridad y precisión en la expresión de otros }\end{array}$ \\
\hline Facilitación & $\begin{array}{l}\text { 8. Generar emociones como ayuda en los procesos de juicio y memoria } \\
\text { 10. Priorizar pensamiento dirigiendo la atención en función del sentimiento } \\
\text { presente } \\
\text { 11. Movilizar emociones para múltiples enfoques } \\
\text { 12. Seleccionar problemas que vayan con su estado emocional actual para } \\
\text { facilitar el proceso cognitivo }\end{array}$ & $\begin{array}{l}\text { 9. Generar emociones propias para entender experiencias de otro } \\
\text { 10. Priorizar pensamiento dirigiendo la atención en función del sentimiento } \\
\text { presenteii } \\
\text { 11. Movilizar emociones para múltiples enfoques } \\
\text { 12. Seleccionar problemas que vayan con su estado emocional actual para } \\
\text { facilitar el proceso cognitivo }\end{array}$ \\
\hline Uso & $\begin{array}{l}\text { 13. Etiquetar emociones y reconocer relaciones entre ellas } \\
\text { 14. Determinar antecedentes, significados y consecuencias de las emociones } \\
\text { 15. Detectar situaciones con potencial de suscitar emociones } \\
\text { 16. Distinguir entre estados y emociones } \\
\text { 17. Entender emociones complejas y mezcladas } \\
\text { 18. Reconocer evolución probable de las emociones, como de ira a } \\
\text { satisfacción } \\
\text { 19. Vislumbrar futuros sentimientos en general o bajo ciertas circunstancias } \\
\text { (pronóstico afectivo)i } \\
\text { 20. Reconocer diferencias culturales en la evaluación de las emocionesi }\end{array}$ & $\begin{array}{l}\text { 13. Etiquetar emociones y reconocer relaciones entre ellas } \\
\text { 14. Determinar antecedentes, significados y consecuencias de las emociones } \\
\text { 15. Detectar situaciones con potencial de suscitar emociones } \\
\text { 16. Distinguir entre estados y emociones } \\
\text { 17. Entender emociones complejas y mezcladas } \\
\text { 18. Reconocer evolución probable de las emociones, como de ira a } \\
\text { satisfacción } \\
\text { 19. Vislumbrar futuros sentimientos en general o bajo ciertas circunstanciasii } \\
\text { 20. Reconocer diferencias culturales en la evaluación de las emocionesii }\end{array}$ \\
\hline Regulación & $\begin{array}{l}\text { 21. Permanecer abierto a sentimientos positivos y negativos y a la información } \\
\text { que éstos proveen } \\
\text { 22. Potenciar o desechar emociones por su utilidad } \\
\text { 23. Supervisar las reacciones emocionales para determinar si son razonables } \\
\text { 24. Evaluar estrategias para mantener, reducir o intensificar una respuesta } \\
\text { emocionali } \\
\text { 25. Gestionar eficazmente sus emociones para lograr el resultado deseado }\end{array}$ & $\begin{array}{l}\text { 23. Supervisar las reacciones emocionales para determinar si son razonables } \\
\text { 24. Evaluar estrategias para mantener, reducir o intensificar una respuesta } \\
\text { emocional } \\
\text { 26. Gestionar eficazmente sus emociones para lograr el resultado deseado }\end{array}$ \\
\hline
\end{tabular}

i Una capacidad anterior subdividida en dos o más.

ii Una nueva capacidad.

iii Al duplicar una capacidad, sugerimos que ésta puede ser aplicada en ambos ámbitos: intra e interpersonal. 
Este modelo se destaca no sólo por ser el único de índole cognitiva, sino que también por invitar a una intervención educativa al estar plasmado mediante verbos - que representan acciones - en infinitivo - forma verbal muy presente en la formulación de objetivos - a diferencia de describir un comportamiento ya existente, como es el caso del modelo de Henderson y Milstein (2005), o sustantivar creencias, actitudes y procederes, como lo hacen los modelos basados en rasgos de personalidad. Además, al organizar las capacidades en orden de complejidad, se permite trazar caminos a seguir a partir de una evaluación diagnóstica inicial. Por tales razones consideramos que éste es el modelo más apropiado para la articulación que estamos sustentando, y como un último argumento a favor de ello describiremos y analizaremos los otros dos modelos más importantes de la inteligencia emocional señalando sus limitaciones. Así, Bar-On (1997, 2000) fue el primero que formuló un instrumento de diagnóstico de la inteligencia emocional, dividido en cinco áreas con tres características-rasgo cada una (véase tabla 2).

Tabla 2. Modelo de inteligencia emocional rasgo de Bar-On

\begin{tabular}{|l|l|l|}
\hline & \multicolumn{1}{|c|}{ Rasgos personales } & Rasgos interpersonales \\
\hline Percepción de uno mismo & $\begin{array}{l}\text { Autoconcepto } \\
\text { Autoconsciencia emocional } \\
\text { Autorrealización }\end{array}$ & \\
\hline Expresión de uno mismo & $\begin{array}{l}\text { Asertividad } \\
\text { Expresión emocional } \\
\text { Independencia }\end{array}$ & Empatía \\
\hline Componente interpersonal & Responsabilidad social \\
\hline Toma de decisiones & $\begin{array}{l}\text { Tolerancia al estrés } \\
\text { Optimismonales }\end{array}$ & \\
\hline Manejo del estrés & Objetividad & \\
\hline
\end{tabular}

Fuente: elaboración propia con datos de Bar-On, 1997.

Este modelo ofrece una interesante conceptualización de la inteligencia emocional sustantivada y centrada en su mayor parte en el mundo interior del individuo. Se destaca por el aspecto de responsabilidad social propio de la perspectiva humanista y determinante a nuestro parecer en todo concepto de inteligencia, ya que al no buscar el bien común, alguien con un cociente intelectual elevado sólo se puede calificar como ingenioso o ágil mentalmente, y se reviste de manto intelectual al dirigir su capacidad mental a un bien mayor que a un simple provecho personal o de un grupo cercano de personas. Por otro lado, algunos rasgos 
mencionados en el modelo - como el optimismopodrían ser lo contrario de la inteligencia si afectan la percepción de la realidad y el análisis cuidadoso de los factores existentes (una limitación similar a los elementos contextuales en el modelo de Henderson y Milstein, 2005).

Además, en un estudio de distintos modelos de la inteligencia emocional ya se ha concluido que de hecho el optimismo no arroja resultados consistentes para confirmar su pertinencia unívoca al constructo de inteligencia emocional (Bisquerra et al., 2015). De igual manera, el incluir la resolución de problemas en el concepto de la inteligencia emocional suscita el cuestionamiento acerca de su clasificación como rasgo, y si la solución de problemas emocionales no abarcaría todo lo relacionado con la inteligencia emocional. En suma, aunque este modelo toca temas muy pertinentes, la estructura no posee la suficiente claridad y coherencia para aportar el elemento organizador a una acción educativa enfocada en el desarrollo del saber ser a la par con el modelo de Peterson y Seligman (2004).
En cuanto al modelo de inteligencia emocional de Goleman (2001), resulta ser muy claro y relativamente sencillo (véase tabla 3). Este autor fue quien popularizó el concepto con el lema "El cociente intelectual te consigue trabajo y el cociente emocional te consigue la promoción". En inglés este lema - IQ gets you hired, EQ gets you promoted - se refiere a la mayor importancia del cociente emocional a largo plazo ya que todos los ámbitos de actividad humana, incluyendo el profesional, implican ser bueno con el manejo de las emociones para permitir el pleno despliegue de su potencial intelectual de una manera asertiva y socialmente adecuada.

Se aprecia que hay coincidencia incluso de palabras exactas con otros modelos: el autoconcepto con el modelo de Henderson y Milstein (2005), así como el liderazgo con el modelo de Peterson y Seligman (2004). Muchos otros elementos designan conceptos similares, aunque no estén expresados con el mismo vocabulario (responsabilidad y trabajo en equipo=ciudadanía; comunicación y gestión de conflictos=inteligencia social, en la clasificación de Peterson y Seligman, 2004, entre otros).

Tabla 3. Inteligencia emocional de Goleman, 2001

\begin{tabular}{|l|l|l|}
\hline \multicolumn{1}{|c|}{ Rasgos personales } & \multicolumn{1}{c|}{ Rasgos interpersonales } \\
\hline Reconocimiento & $\begin{array}{l}\text { Autoconsciencia personal } \\
\text { Autoevaluación } \\
\text { Autoconfianza }\end{array}$ & $\begin{array}{l}\text { Empatía } \\
\text { Orientación al cliente } \\
\text { Conciencia organizacional }\end{array}$ \\
\hline Regulación & $\begin{array}{l}\text { Autocontrol emocional } \\
\text { Formalidad } \\
\text { Responsabilidad } \\
\text { Adaptabilidad } \\
\text { Motivación de logro } \\
\text { Iniciativa }\end{array}$ & $\begin{array}{l}\text { Desarrollo de los demás } \\
\text { Influencia } \\
\text { Comunicación } \\
\text { Gestión de conflictos } \\
\text { Liderazgo } \\
\text { Catalización de cambio } \\
\end{array}$ \\
& $\begin{array}{l}\text { Construcción de alianzas } \\
\text { Trabajo en equipo }\end{array}$ \\
\hline
\end{tabular}

Fuente: elaboración propia con datos de Goleman, 2001. 
En el marco de análisis crítico destacamos que, además de estar orientado al mundo de la empresa y tener por tanto limitada aplicabilidad en la educación humanista, tiene poco sustento científico (Bisquerra et al., 2015): el modelo de Goleman (2001) combina el paradigma cognitivo (inteligencia), conductista (comportamiento), constructivista (competencias) y de desarrollo (personalidad), mientras que algunos autores señalan que son líneas de investigación con bases epistemológicas incompatibles (Fragoso-Luzuriaga, 2015). Aunque consideramos que sí se pueden tender puentes entre algunos de estos paradigmas (y este análisis es un esfuerzo en esa dirección, precisamente, señalando la complementariedad de rasgos de personalidad con el acercamiento cognitivo hacia su desarrollo), el modelo de Goleman no sustenta la heterogeneidad de sus elementos y los agrupa a manera de categorías homogéneas, por lo que, a pesar de tener éxito en el ámbito de coaching y formación continua en empresas, no ha llamado mucha atención en el ámbito científico (Bisquerra et al., 2015).

Otra limitación del modelo de Goleman (2001) se basa en el hecho de que la inteligencia no está directamente relacionada con el comportamiento (Mayer, Caruso y Salovey, 2016), mientras que este modelo hace ver demasiado directa la relación entre la inteligencia emocional, el comportamiento modificado y sus resultados laborales apremiantes. En cambio, los modelos de personalidad formulados desde la resiliencia sí ofrecen una base epistemológica más sólida y una perspectiva más amplia, ofreciendo camino a una vida plena (saber ser), y no sólo recompensa monetaria (saber hacer). Y aunque el modelo de Peterson y Seligman (2004) también requeriría de ser enfocado al ámbito de la academia, siempre es preferible delimitar un modelo amplio en vez de una reconstrucción mayor que necesitarían los modelos de la inteligencia emocional como rasgo de personalidad aquí analizados.

\section{Modelo integrador}

En este apartado se presenta el modelo integrador resultado de una revisión teórica en el marco de investigación doctoral en curso. El propósito es dar a conocer una propuesta para el desarrollo del $s a^{-}$ ber ser donde se fundamenta que los dos conceptos centrales analizados - resiliencia e inteligencia emocional- resultan complementarios, debido a que ambos llegan a estudiarse como rasgo de personalidad y como proceso (aunque el proceso resiliente se relaciona más con los recursos del contexto, mientras que el proceso de desarrollo de inteligencia emocional se basa en la ordenación jerárquica de capacidades cognitivas que la constituyen). Aquí retomamos el modelo de rasgos de personalidad resilientes más completo y relativamente libre de sesgos culturales (Peterson y Seligman, 2004) y el modelo de inteligencia emocional de acercamiento cognitivo por ser el único de esa índole en ambos paradigmas, y porque además el contexto socio-cultural de los educandos no suele estar al alcance del docente por lo cual no debería formar parte del modelo para el desarrollo del saber ser desde el aula (Mayer y Salovey, 1997). Argumentamos que el proceso de desarrollo de inteligencia emocional puede de hecho aplicarse a todas las fortalezas personales que componen la clasificación de Peterson y Seligman (2004), donde la inteligencia emocional es de hecho una de las fortalezas.

El modelo es innovador ya que en el estado del arte no hemos encontrado equivalentes: existen algunos modelos mixtos o compuestos en la investigación aplicada de la resiliencia, los cuales básicamente utilizan varios modelos de la resiliencia simultáneamente en el marco de investigaciones a nivel de escuela completa (Lamata, 2012; Mateu et al., 2010, entre otros). ${ }^{4}$ No se observa este tipo de estudios en el ámbito de inteligencia emocional, puesto que los

${ }^{4}$ El llamado "whole school approach" que abarca a los ámbitos administrativo y educativos a la vez. 
investigadores suelen elegir un solo modelo para su estudio. Finalmente, otros estudios que han referido ambos conceptos se enfocan en la correlación entre ellos bajo concepto de variables distintas (Colop, 2010; Cejudo, López-Delgado y Rubio, 2016; entre otros).

Resumiendo las afinidades entre los dos constructos, apuntamos a que los modelos de la resiliencia ofrecen un repertorio impresionante de rasgos de personalidad que son parte de un estado personal empoderado frente a posibles dificultades de distintos ámbitos de la vida. Retoman todo lo presente en los modelos de la inteligencia emocional como rasgo de personalidad y agregan más. Es interesante señalar que la manifestación de la resiliencia en los individuos vulnerables se atribuye a la existencia de apoyo afectivo en el contexto social y a la fortaleza emocional propia; por tanto, este concepto se podría clasificar en resiliencia interpersonal e intrapersonal. La diferencia con la inteligencia emocional sería la perspectiva desde la que se originó esta línea de investigación: en un principio el análisis de la resiliencia se enfocó principalmente en riesgos interpersonales y debilidades intrapersonales, los llamados factores de riesgo del contexto y de la persona (Werner y Smith, 1982), es decir desde el enfoque de atención a contextos o rasgos disfuncionales. De hecho, es una línea de investigación muy presente en la psicología clínica incluso en este siglo (Ezpeleta, 2005).

Un supuesto importante del enfoque de los dos modelos retomados es que buscan fortalecer a las personas que ya son fuertes, como es el caso de los estudiantes universitarios por formar parte de la élite intelectual del país. El cómo de este fortalecimiento preventivo desde un contexto de baja adversidad (no eventos trágicos, no guerras u otros eventos traumatizantes en los que se ha estudiado la resiliencia) se articula dentro de este modelo integrador para el desarrollo del saber ser. Su potencial eficacia se apoya en los últimos hallazgos de los investigadores - tanto en resiliencia como en inteligencia emocional - los cuales demuestran que los rasgos de personalidad no son independientes entre sí, y la modificación de uno puede involucrar cambio correlacionado de otros, por lo que podemos decir que las perspectivas de intervención educativa desde este enfoque son altamente prometedoras.

$\mathrm{Al}$ evaluar cuán realizado está el potencial de las fortalezas, se vislumbraría el relieve de las fortalezas del educando permitiendo elegir la senda para fomentar aún más las fortalezas desarrolladas - que aún no están en su pleno potencial-, buscando una potenciación en paralelo de otros rasgos correlacionados menos desarrollados, ya de manera indirecta. Esto ofrece un nuevo giro para el desarrollo de la personalidad, ya que es mucho más atractivo fortalecer algo en lo que ya somos buenos en vez de verse obligado a trabajar con algo en lo que no somos tan buenos, etiquetados de desventajados, poco aptos o ignorantes, y condicionados a aspirar a mejorar un poco para quizá alcanzar el promedio sin mucha esperanza para destacar.

Abogando porque las propuestas de desarrollo del saber ser en el aula deben cumplir ciertos requisitos de factibilidad, señalaremos cuatro de ellos que consideramos imprescindibles: 1) orientar las actividades con base en conceptos estructurados científicamente corroborados, a manera de otros contenidos que solemos presentar en clases universitarias; 2) enfocarse en aquellas características del estudiante que están al alcance del docente dentro del aula; 3) incluir un acercamiento cognitivo a la mediación de aprendizajes, más allá del apoyo personal del docente al alumnado en su papel de tutor de resiliencia, y 4) permitir una evaluación diagnóstica y formativa para continua adecuación y mejora de la actividad didáctica y el aprendizaje.

Consideramos que la línea de investigación sobre la resiliencia en su enfoque positivo ofrece herramientas útiles para cumplir con los primeros dos requisitos, mientras que el área cognitiva de la línea de investigación sobre la inteligencia emocional 
abona a los tercero y cuarto: además de aportar un entendimiento detallado del desarrollo cognitivo de elementos resilientes, tiene el potencial de orientar una acción constructiva sobre diferentes dimensiones a distintos niveles susceptibles de ser evaluados. La presentación gráfica del modelo integrador resultante se muestra en la figura 8 , donde el plano horizontal es definido en términos de los elementos que constituyen el saber ser y el vertical refleja su desarrollo. La silueta de una montaña hace alusión al crecimiento personal que se da al potenciar las distintas capacidades y desarrollar más fortalezas.

Figura 8. Bosquejo del modelo integrador para el desarrollo del saber ser del estudiante universitario

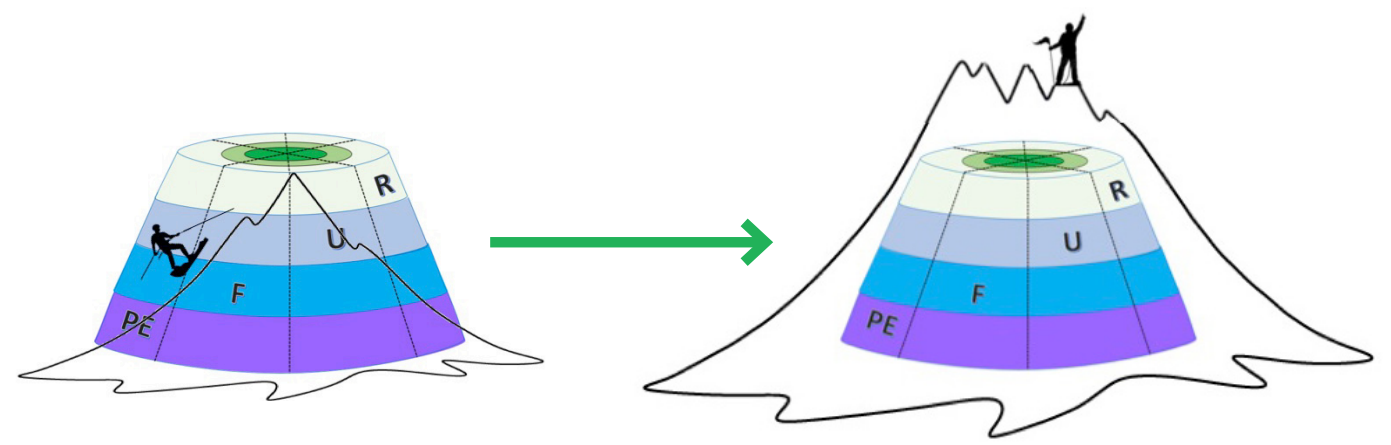

Fuente: elaboración propia.

Esta combinación de dos modelos bidimensionales en un modelo compuesto tridimensional proporciona una mayor claridad en cuanto a la dirección de acción educativa y para la evaluación de su contribución el desarrollo del saber ser. Una prueba de las 24 fortalezas con evaluación de su desarrollo en términos de las cuatro áreas del modelo PEFUR puede esclarecer el punto de partida, ayudar a establecer el punto de llegada y definir cuáles son las áreas idóneas para la acción educativa, como se aprecia en la figura 9.

\section{Figura 9. Visualización del diagnóstico posible}

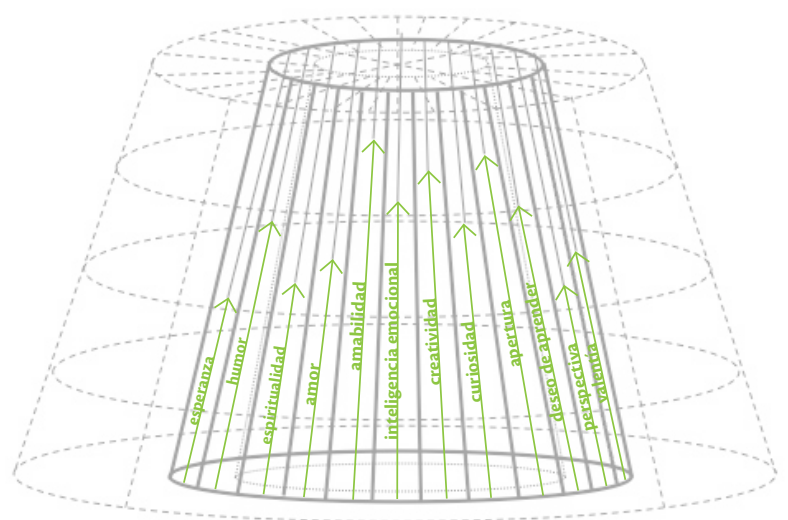


Imaginando que la figura 9 representa los resultados de un estudiante promedio, vislumbremos su articulación con los contenidos de una clase universitaria de idiomas: en términos generales sugeriríamos proceder desde el enfoque que algunos investigadores llaman indagación apreciativa, es decir, aquella que se centra en los puntos fuertes (White y Murray, 2015). Habiendo aclarado esto, propondríamos, por un lado, que se trabaje con el desarrollo de las fortalezas intermedias-avanzadas que aún no alcanzan la última etapa de su desarrollo. Así, el sentido del humor, el manejo de emociones y la curiosidad son fortalezas bastante desarrolladas en nuestro ejemplo, por lo tanto, el estudiante se sentiría cómodo trabajándolas. Por otro lado, puesto que estas fortalezas en el nivel de desarrollo medio-alto están relacionadas con otras fortalezas - en las que refieren un nivel inferior-, el desarrollo de las primeras podría conllevar potenciación de las segundas (como sería el caso de la curiosidad, que al ser potenciada conllevaría el desarrollo de la perspectiva).

En nuestro ejemplo, las tres fortalezas clasificadas como de desarrollo medio-alto superan el ámbito experiencial. Como consecuencia, en una intervención educativa se trabajaría en la construcción de capacidades desde el ámbito estratégico, en el tercer nivel del modelo PEFUR: área de comprensión y uso de las emociones y las ocho capacidades que le corresponden. Dependiendo del nivel de idioma que poseen los estudiantes, algunas capacidades o fortalezas se prestarían más a una articulación con los contenidos regulares.

Por ejemplo, en un nivel básico de idioma se trabajaría la fortaleza "manejo de las emociones" en el entendimiento con el vocabulario de las emociones, semejanzas y diferencias entre estados emocionales, y en su uso mediante el análisis de su presencia en los entornos conocidos al estudiante. En una clase de nivel intermedio se podría trabajar con capacidad de comprensión de la fortaleza "curiosidad": generar hipótesis sobre cuáles son sus motivos, cómo mantenerla, qué emociones podrían estar presentes, cómo podrían evolucionar, qué consecuencias podría tener en el aprendizaje universitario y/o desempeño profesional, así como en el ámbito personal. Finalmente, en un nivel avanzado de idioma para la comprensión y uso de "sentido de humor" se haría un análisis comparativo intercultural: su pertinencia, uso culturalmente aceptable, temas de los sketchs cómicos más populares e improvisación sobre algún tema.

Este desarrollo hipotético se basó en tres fortalezas de nivel medio-alto identificadas en una prueba individual. En la práctica áulica, las fortalezas concretas por trabajar se identificarían con base en los resultados más recurrentes del grupo, quizá sean más de tres; entonces sería oportuno consensuar con el grupo cuántas y cuáles fortalezas se desea trabajar, lo cual permitiría conciliar las necesidades comunes objetivadas con las metas personales. Asimismo, en el ejemplo nos centramos en la aplicación del modelo en una clase de idiomas, pero se pueden vislumbrar diferentes maneras de trabajarlo en clase de literatura e historia con análisis de distintos personajes, en arte y cultura con el estudio de diversas formas de expresión emocional, y en muchas otras materias de tronco común según el contenido y el enfoque propios de cada una.

Aquí sólo bosquejamos una ventanita al mundo de posibilidades que se abre al formular este modelo, cuyo lado fuerte es su naturaleza sistemática que lo hace apto para fundamentar en él un plan de acción estratégico sobre un plano tridimensional, con punto de partida y objetivos claramente formulados. Cabe mencionar que, al implementar este modelo en las aulas, los maestros también necesitan recibir una formación en el sustento teórico del modelo con un taller con dinámicas grupales relacionadas con su aplicación, como bien lo señalan Cabello, Ruiz y Fernández (2010). En ocasiones resulta novedoso entender que la valentía también es defender su opinión en público, o que la creatividad no se limita al arte y se expresa de la capacidad de encontrar soluciones alternativas a problemas comunes: por ello, 
una preparación conceptual del docente es indispensable para una práctica coherente.

\section{A manera de cierre}

Como resultado de esta revisión concluimos que los recientes desarrollos de la psicología educativa desde los enfoques cognitivo, de desarrollo y positivo han formulado modelos con gran potencial para la práctica docente en el área de desarrollo cognitivo del saber ser del estudiante. No obstante, aún hacen falta más estudios aplicados para realizar dicho potencial en distintos niveles y ámbitos educativos. Para ello, la psicología educativa, que hasta ahora ha sido muy teórica y orientada a contexto socioafectivo muy amplio de los agentes educativos, debería privilegiar el acercamiento cognitivo al desarrollo emocional y valoral de los educandos en el contexto académico.

La psicología educativa aplicada iría rumbo a desarrollos didácticos para el docente, quien hoy en día es llamado a contribuir al desarrollo íntegro de sus alumnos, pero al mismo tiempo se ve abrumado por un rango creciente de obligaciones laborales, inmerso en el proceso al que algunos autores se refieren como la intensificación del trabajo (término planteado inicialmente por Marx, 1867). Como lo argumentan algunos autores, no es que los docentes no sean capaces de tomar la iniciativa y aplicar nuevos conceptos, pero es frecuente la situación donde la institución educativa no otorga tiempo ni espacio para la actividad indagatoria a los miembros de su plantel, quienes se encuentran atrapados en un ritmo laboral que imposibilita un estudio y análisis rigurosos de propuestas teóricas innovadoras, desarrollo de propuestas aplicadas y su divulgación (Hargreaves, 2005; Pérez-Zapata, 2015, entre otros).

Es precisamente por lo que los que sí estamos en condiciones de hacer la investigación, deberíamos asumir la responsabilidad de llevar nuestros hallazgos a los colegas de una manera accesible y claramente articulada, actuar para subsanar las consecuencias de industrialización de la educación en un régimen capitalista basado en estadísticas, performance y otros acercamientos cuantitativos a la calidad educativa. Los investigadores tenemos la oportunidad de llevar a cabo recopilación teórica, análisis y formulación de propuestas concretas para el aula, y balancear la búsqueda de un impacto social de calidad (mejoras reales en nuestra comunidad) con el de cantidad (como el volumen de producción o eficiencia terminal que nos pueden exigir ciertas instituciones). Debemos integrarnos a la triada de actores educativos profesor-estudiante-padre de familia para favorecer la congruencia de innovaciones educativas locales.

El presente artículo relacionado con el desarrollo personal del estudiante en educación superior fue escrito precisamente con la finalidad de compartir el análisis de algunos conceptos cuya comprensión es a veces superficial, puesto que su interpretación se basa en ideas o supuestos que no están relacionados con su fundamentación teórica y epistemológica. Es por lo que, en los cursos de inteligencia emocional, por ejemplo, a veces nos encontramos cantando y bailando sin que ello conlleve algún tipo de análisis, sin lograr un objetivo educativo ni fomentar alguna competencia para la vida. Algunas actividades de fomento de inteligencia emocional parecen ser técnicas de relajación antes que secuencias didácticas. En ocasiones malinterpretamos conceptos y sustituimos lo dinámico por lo lúdico incluso en educación superior, sólo dejamos fluir libremente las emociones en un espacio que pretendemos sea de educación emocional. En resumen, el aspecto de inteligencia llega a ausentarse de esta llamada práctica de inteligencia emocional.

Aclararemos que no es que condenemos dichas prácticas o las buenas intenciones de quienes las llevan a cabo en las aulas con sus alumnos, lo que cuestionamos es la denominación de éstas como educativas, enfocadas en el desarrollo de algún tipo de inteligencia. Esta manera de interpretar el desarrollo de la inteligencia emocional ha llevado incluso a algunos investigadores mexicanos a cuestionar el 
mismo concepto, o su pertinencia en la educación formal (Mestre et al., s/f, entre otros).

Aquí abogamos por una visión más científica y estructurante de aquello que llamamos educación emocional y socio-valoral, parte del aprender a ser, e invitamos a ir más allá de pausas para el esparcimiento personal o esporádicas pláticas motivacionales que hemos observado en nuestro contexto, hacia un plan curricular bien fundado y estructurado y una planeación de clase que contenga verdaderas contribuciones al fomento de competencias para la vida.

El modelo que aquí presentamos está dirigido hacia este gran objetivo, y se encuentra en la etapa de elaboración de pruebas diagnósticas y estrategias de mediación de aprendizaje relacionadas con ello. Se podría decir que estamos en la etapa creativa donde generamos una propuesta nueva a partir de los elementos existentes para su uso en la planeación de clase durante un ciclo escolar dado. La etapa donde se buscará llegar a nivel de innovación (aplicación curricular y didáctica de las propuestas creativas según Ortega, 2017) aún está por delante. Vislumbramos un elefante en lo que a primera vista parecía un sombrero, pero sólo ha sido la primera hoja del álbum de El Principito.

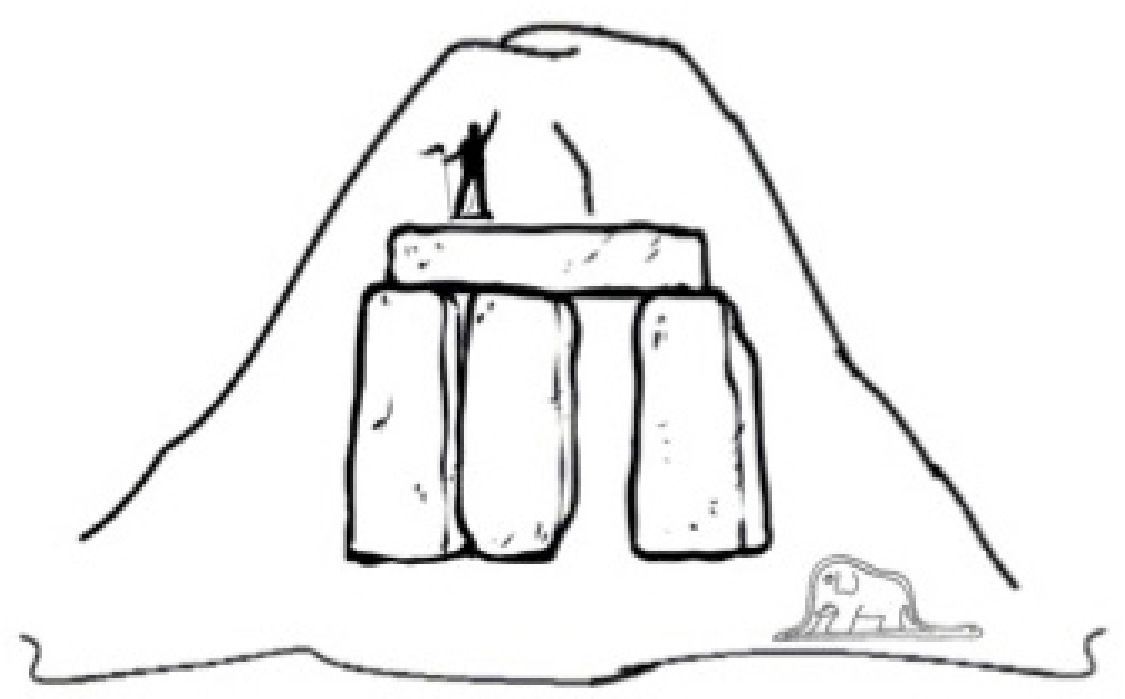




\section{Referencias}

Alonso, Catalina y Domingo Gallego (2008), Cuestionario Honey-Alonso de Estilos de Aprendizaje, <www. estilosdeaprendizaje.es>, [Consulta: mayo de 2017].

Bar-On, Reuven (1997), Bar-On Emotional Quotient Inventory: Technical Manual, Canada, Toronto, Multi Health System.

Bar-On, Reuven y James Parker (Eds.) (2000), Handbook of Emotional Intelligence, San Francisco, C.A., Jossey Bass.

Bisquerra, Rafael, Juan Carlos Pérez y Esther García (2015), Inteligencia emocional en educación, Madrid, Editorial Síntesis.

Cabello, R., D. Ruiz y P. Fernández (2010), "Docentes emocionalmente inteligentes", Revista Electrónica Interuniversitaria de Formación del Profesorado REIFOP, núm. 13 (1), pp. 41-49.

Carrido, Mario y Elvira Talavera (2008), "Estado de la Investigación en España sobre la Inteligencia Emocional en el ámbito educativo", Revista Electrónica de Investigación Psicoeducativa, núm. 15, vol. 6(2), pp. 400-420.

Cejudo, Javier, Luz López-Delgado y Jesús Rubio (2016), "Inteligencia emocional y resiliencia: su influencia en la satisfacción con la vida en estudiantes universitarios", Anuario de Psicología, núm. 46, pp. 51-57.

Colop, Vilma (2010), Relación entre inteligencia emocional y resiliencia, Tesis de licenciatura, Universidad Rafael Landívar, Guatemala, <http://biblio3.url.edu.gt>, [Consulta: mayo de 2017].

Delors, Jacques, In'am Al Mufti, Isao Amagi, Roberto Carneiro, Fay Chung, Bronislaw Geremek, William Gorham, Aleksandra Kornhauser, Michael Manley, Marisela Padrón Quero, Marie-Angélique Savané, Karan Singh, Rodolfo Stavenhagen, Myong Won Suhr y Zhou Nanzhao (1996), La educación encierra un tesoro. Informe a la UNESCO de la Comisión Internacional sobre la Educación para el siglo XXI presidida por Facques Delors, Santillana, Ediciones UNESCO.

Ezpeleta, Lourdes (Coord.) (2005), Factores de riesgo en psicopatología del desarrollo, España, Barcelona, Masson.

Fragoso-Luzuriaga, Rocío (2015), "Inteligencia emocional y competencias emocionales en educación superior, ¿un mismo concepto?", Revista Iberoamericana de Educación Superior (RIES), núm. 16(VI), pp. 110-125.

Gancedo, Mariana (2007), Virtudes y Fortalezas: el revés de la trama. Psicodebate, Psicología, Cultura y Sociedad, 7, pp. 67-80, <https://dialnet.unirioja.es/>, [Consulta: mayo de 2017].

Gardner, Howard (1983), Frames of Mind: The theory of multiple intelligences, United States of America, New York, Basic Books.

Goleman, Daniel (1995), Emotional intelligence, United States of America, New York, Bantam Books.

Goleman, Daniel (2001), "An EI-based Theory of Performance", en Cherniss, C. \& Goleman, D (Eds.), The Emotionally Intelligent Workplace, San Francisco, C.A.: Jossey-Bass, pp. 27-44.

Hargreaves, Andy (2005), Profesorado, cultura y postmodernidad: cambian los tiempos, cambia el profesorado, Madrid, Morata, <www.comie.org.mx/>, [Consulta: mayo de 2017].

Henderson, Nan y Mike Milstein (2005), Resiliencia en la escuela, Barcelona, Paidós Ibérica.

Lamata, Carmen (2012), La escuela como tutora de resiliencia social: Diseño y desarrollo del programa REVELA-T, tesis doctoral, España, Universidad Complutense de Madrid.

Mateu, Rosa, Mónica Renedo, José Manuel Gil y Antonio Caballer (2010), ¿Qué es la resiliencia? Hacia un modelo integrador, fornadas de fomento de la investigación, España, Universidad Jaume.

Marx, Karl (1867), El capital, Tomo I, <www. alejandriadigital.com>, [Consulta: mayo de 2017].

Mayer, John y Peter Salovey (1997), "What is emotional intelligence?" en P. Salovey \& D. Sluyter (Eds.), Emotional Development and Emotional Intelligence: Implications for Educators, pp. 3-31, Nueva York, Basic Books.

Mayer, John y Peter Salovey (2007), “¿Qué es Inteligencia Emocional?", en J. Mestre y P. Fernández-Berrocal. (Coords.), Manual de Inteligencia Emocional, pp. 23-43, España, Madrid, Pirámide.

Mayer, John, David Caruso y Peter Salovey (2016), "The 
Ability Model of Emotional Intelligence: Principles and updates", Emotion Review, octubre, núm. 8(4), pp. 290-300.

Mestre, José, María Guil, María Carreras y Paloma Braza (s/f), "Cuando los constructos psicológicos escapan del método científico: El caso de la inteligencia emocional y sus implicaciones en la validación y evaluación", Revista Electrónica de Motivación y Emoción, <http://reme.uji.es/ articulos/amestj1961605100/texto.html>, [Consulta: mayo de 2017].

Negrete, Juan-Antonio (2013), Cuatro filosofias de la educación, video, Editorial Manuscritos, <www.youtube. com>, [Consulta: mayo de 2017].

O’Brien, Lynn (1990), Test para determinar el Canal de Aprendizaje de preferencia, <http://www.iafi.com.ar/pnl/ ejercicios-pnl/test-canalpreferencia.pdf>, [Consulta: mayo de 2017].

Ortega, Joel (2017), La creatividad en el sistema educativo mexicano, marco teórico, documento sin publicar, México, Tlaxcala, UATx.

Orteu, Meritxell (2012), Escuelas resilientes, [https:// www.avntf-evntf.com/wp-content/uploads/2016/12/ OrteuM.Trab_.3BI1 112.pdf]

Pleshakova, Victoria (2009), "The Importance of Teaching Humanities in Higher Education Institutions: in Defense of Liberal Arts Education", Graduate College Dissertations and Theses, 182, <https://scholarworks. uvm.edu/graddis/182>, [Consulta: mayo de 2017].

Pérez-Zapata, Oscar (2015), Trabajo sin límites, salud insostenible: la intensificación del trabajo del conocimiento, tesis doctoral, <http://eprints.sim.ucm.es/28065/1/ T35635.pdf>, [Consulta: mayo de 2017].

Peterson, Christopher y Martin Seligman (2004), Character Strengths and Virtues: A handbook and classification, United States of America, Washington D.C., American Psychology Association.

Romero, María-Elena (2016), Nepoualtzitzin: La sabiduría de contar en el mundo mesoamericano. Elementos teóricos y prácticos de la matemática prehispánica, México, Palibrio.

Salovey, Peter y John Mayer (1990), "Emotional intelligence", Imagination, Cognition and Personality, núm. 9, pp. 185-211.

Seligman, M. (2002), Authentic Happiness: Using the New Positive Psychology to Realize Your Potential for Lasting Fulfiment, United States of America, New York, NY, Free Press.

Seligman, Martin (2012), Flourish: A Visionary New Understanding of Happiness and Well-being, United States of America, Atria Books.

Vanistendael, Stefan y Jacques Lecomte (2002), La felicidad es posible. Despertar en niños maltratados la confianza en sí mismos: construir la resiliencia, España, Barcelona, Gedisa.

Werner, Emmy y Ruth Smith (1982), Vulnerable but invincible. A longitudinal study of resilient children and youth, United States of America, New York, McGraw-Hill.

White, Mathew y Simon Murray (Eds.) (2015), Evidencebased approaches to positive education in schools: implementing a strategic framework for well-being in schools, Netherlands, Springer Press. 